\title{
VALIDASI PERANGKAT PEMBELAJARAN IPA BERBASIS INKUIRI TERBIMBING UNTUK MELATIHKAN KETERAMPILAN MEMECAHKAN MASALAH PADA POKOK BAHASAN CERMIN
}

\author{
Dir Indarmaji ${ }^{1)}$, Endang Susantini' ${ }^{2)}$, Tjipto Prastowo ${ }^{3)}$ \\ ${ }^{1)}$ Mahasiswa Program Studi Pendidikan Sains, Program Pascasarjana Universitas Negeri Surabaya \\ ${ }^{2), 3)}$ Dosen Pascasarjana Prodi Pendidikan Sains Univesrtitas Negeri Surabaya \\ E-mail:t_prastowo@yahoo.com
}

\begin{abstract}
This research aimed to produce science learning material guided inquiry base a feasible to practice problem solving skills on topic mirror. The learning material was tested to VIII grade students of SMPN 1 Sedati Sidoarjo of the academic year 2014/2015. This research was one which used 4-D model development that was modified 3D (dissemination stage is not done). The test device used one group pretest-posttest design. Result of the research showed validity of learning material well categorized and could be used in learning with few revisions resulted realibility in RPP assessment, worksheet, student learning result and problem solving skills as much as 98\%, 98,70\%, (95,80\% and 98,60\%), and 98,82\%. Based on result, research discussion, could be summarized that guided inquiry based science learning material to practice problem solving skills on topic mirror is feasible to be used in learning.
\end{abstract}

Keywords: Learning Material, Guided Inquiry, Problem Solving Skills.

\begin{abstract}
Abstrak: Penelitian ini bertujuan untuk menghasilkan perangkat pembelajaran IPA berbasis inkuiri terbimbing yang layak untuk melatihkan keterampilan memecahkan masalah pada pokok bahasan cermin. Perangkat pembelajaran tersebut diujikan pada siswa kelas VIII SMPN 1 Sedati Sidoarjo tahun pelajaran 2014/2015. Penelitian ini merupakan penelitian pengembangan dengan model 4-D yang dimodifikasi menjadi 3D (tahap desiminasi tidak dilakukan). Rancangan ujicoba perangkat menggunakan one group pretest-posttest design. Hasil penelitian menunjukkan validitas perangkat pembelajaran berkategori baik dan dapat digunakan dalam pembelajaran dengan sedikit revisi diperoleh reliabilitas penilaian RPP, LKS, hasil belajar siswa, dan keterampilan memecahkan masalah sebesar 98\%, 98,70\%, (95,80\% dan 98,60\%), dan 98,82. Berdasarkan hasil dan diskusi penelitian, dapat disimpulkan bahwa perangkat pembelajaran IPA berbasis inkuiri terbimbing untuk melatihkan keterampilan memecahkan masalah pada pokok bahasan cermin layak digunakan dalam pembelajaran.
\end{abstract}

Kata kunci: Perangkat Pembelajaran, Inkuiri Terbimbing, Keterampilan Memecahkan Masalah.

\section{PENDAHULUAN}

Kurikulum 2013 merupakan salah satu produk penyempurnaan dan pengembangan kurikulum di Indonesia yang menekankan pentingnya keseimbangan kompetensi sikap, pengetahuan dan keterampilan. Siswa diajak menjadi berani untuk mencari sumber belajar lain yang tersedia dan terbentang luas di sekitarnya. Berbeda dengan pelaksanaan kurikulum sebelumnya, sisi kreativitas siswa kurang disentuh, Kurikulum 2013 yang diterapkan mulai Tahun Ajaran 2013/2014 akan lebih mendorong siswa untuk kreatif. Pemerintah telah menyiapkan semua perangkat pendukung sebagai implementasi dari kurikulum 2013, seperti silabus yang memuat kompetensi inti (KI) dan kompetensi dasar (KD), akan tetapi rencana pelaksanaan pembelajaran (RPP) tetap menjadi kewajiban guru dengan mengacu kepada silabus yang telah disediakan. Peran guru diperlukan untuk meningkatkan hasil proses pembelajaran terutama dalam mempersiapkan perangkat pembelajaran yang mengarah pada penyelesaian masalah dengan tetap mengacu pada kompetensi dasar (KD) yang telah ada. Salah satu model pembelajaran yang disarankan untuk diterapkan dalam pelaksanaan pembelajaran IPA adalah dengan mengunakan model inkuiri terbimbing.

Keterampilan memecahkan masalah dalam pembelajaran IPA adalah penting dilakukan, maka salah satu upaya untuk melatihkan keterampilan memecahkan masalah siswa adalah melalui pembelajaran dengan model inkuiri terbimbing. Model inkuiri terbimbing menekankan peran guru dalam membimbing siswa melakukan kegiatan dengan memberi pertanyaan awal dan mengarahkan pada suatu diskusi.

Guru mempunyai peran aktif dalam menentukan permasalahan dan tahap-tahap pemecahannya. Siswa 
belajar lebih beorientasi pada bimbingan dan petunjuk dari guru hingga siswa dapat memahami konsep-konsep pelajaran, siswa akan dihadapkan pada tugas-tugas yang relevan untuk diselesaikan baik melalui diskusi kelompok maupun secara individual agar mampu menyelesaikan masalah dan menarik suatu kesimpulan secara mandiri.

Pokok bahasan yang dikembangkan dalam perangkat pembelajaran ini adalah cermin. Pokok bahasan tersebut erat kaitannya dengan masalah kehidupan sehari-hari, misalnya mengapa ketika seseorang bercermin dapat melihat wajahnya di cermin, mengapa mobil yang jauh berada di belakang bisa terlihat di kaca spion, mengapa lampu mobil dibuat melengkung. Siswa diharapkan lebih aktif mengajukan pertanyaan setelah mendalami materi yang berhubungan dengan kehidupan sehari-hari untuk melatihkan keterampilan memecahkan masalah melalui proses inkuiri terbimbing. Pokok bahasan cermin akan lebih menarik dan bermakna apabila disajikan dengan menggunakan model pembelajaran berbasis inkuiri terbimbing untuk melatihkan keterampilan memecahkan masalah siswa. Hal ini didasarkan pada kompetensi dasar ketrampilan yang mewajibkan siswa harus melakukan percobaan untuk menyelidiki sifatsifat cermin dan hubungannya dengan berbagai bentuk cermin yang dihubungkan dengan fenomena kehidupan sehari-hari.

Berdasarkan uraian di atas, maka tujuan umum penelitian ini adalah untuk menghasilkan perangkat pembelajaran IPA berbasis inkuiri terbimbing yang layak untuk melatihkan kerampilan memecahkan masalah pada pokok bahasan cermin.

\section{METODE PENELITIAN}

Penelitian ini diawali dengan validasi perangkat pembelajaran untuk mengetahui validitas perangkat pembelajaran yang dikembangkan, yaitu meliputi validitas rencana pelaksanaan pembelajaran (RPP), lembar kegiatan siswa (LKS), hasil belajar siswa, dan keterampilan memecahkan masalah. Perangkat pembelajaran yang telah memenuhi syarat validitas, selanjutnya diujicobakan di kelas VIII SMPN Sedati 1 Sidoarjo untuk memperoleh masukan sebagai bahan perbaikan.

Lembar validasi perangkat pembelajaran digunakan untuk memperoleh data validitas perangkat pembelajaran yang dikembangkan peneliti. Lembar validasi diisi oleh pakar (validator) yang menelaah dan menilai aspek isi, format, dan bahasa dalam perangkat pembelajaran yang dikembangkan oleh peneliti. Instrumen lembar validasi yang dikembangkan peneliti adalah: perangkat rencana pelaksanaan pembelajaran (RPP), lembar kegiatan siswa (LKS), hasil belajar siswa dan keterampilan memecahkan masalah.
Perhitungan reliabilitas penilaian perangkat dihitung dengan menggunakan rumus sebagai berikut:

Percentage of agreement $(R)=100 \% x\left[1-\frac{A-B}{A+B}\right]$

Keterangan:

A : Skor tertinggi oleh validator yang memberikan nilai tinggi

B : Skor terendah oleh validator yang memberikan nilai rendah

Instrumen dikatakan baik apabila reliabilitas yang diperoleh $\geq 0,75$ atau $\geq 75 \%$ (Borich, 1994 dalam Ibrahim, 2005). Uji coba dilakukan pada siswa kelas VIII SMPN 1 Sedati, Sidoarjo pada semester ganjil tahun pelajaran 2014/2015.

Pengumpulan data dalam penelitian ini menggunakan teknik validasi perangkat, perangkat pembelajaran yang dikembangkan lebih dahulu direvisi oleh pembimbing dan divalidasi oleh para pakar (validator). Lembar validasi perangkat pembelajaran digunakan untuk memperoleh data validitas perangkat pembelajaran yang dikembangkan peneliti. Lembar validasi diisi oleh validator yang menelaah dan menilai aspek isi, format, dan bahasa. Lembar validasi yang dikembangkan oleh peneliti meliputi perangkat rencana pelaksanaan pembelajaran (RPP), lembar kegiatan siswa (LKS), hasil belajar siswa, dan keterampilan memecahkan masalah.

Analisis data yang digunakan dalam penelitian ini adalah analisis validitas perangkat pembelajaran, terdiri dari: RPP, LKS, Tes Hasil Belajar Pengetahuan, dan Tes keterampilan memecahkan masalah yang dikembangkan selanjutnya ditelaah oleh pembimbing kemudian di validasi oleh validator untuk memberikan penilaian terhadap kelayakan untuk dijadikan perangkat pembelajaran. Dalam penelitian ini passing grade adalah skor rata-rata $(P)$ dari hasil penilaian para validator, kemudian disesuaikan dengan kriteria penilaian perangkat sebagai berikut:

Tabel 1. Kriteria pengkategorian penilaian perangkat pembelajaran

\begin{tabular}{|l|l|}
\hline Interval Skor & Kategori Penilaian \\
\hline $3,5 \leq \mathrm{P} \leq 4,0$ & Baik / Valid \\
\hline $2,5 \leq \mathrm{P}<3,5$ & Cukup Baik / Cukup Valid \\
\hline $1,5 \leq \mathrm{P}<2,5$ & Kurang Baik/ Kurang Valid \\
\hline $1,0 \leq \mathrm{P}<1,5$ & Tidak Baik/ Tidak Valid \\
\hline
\end{tabular}

(diadaptasi dari Ratumanan \& Laurens, 2006)

\section{HASIL PENELITIAN DAN DISKUSI}

A. Validasi Rencana Pelaksanaan Pembelajaran (RPP)

Rencana Pelaksanaan Pembelajaran (RPP) adalah rencana kegiatan pembelajaran tatap muka untuk satu pertemuan atau lebih. Hasil penilaian terhadap validasi RPP disajikan dalam Tabel 2. 
Tabel 2. Hasil penilaian kualitas RPP

\begin{tabular}{|l|l|l|l|l|l|}
\hline \multirow{2}{*}{ No } & \multirow{2}{*}{$\begin{array}{l}\text { Aspek yang } \\
\text { dinilai }\end{array}$} & \multicolumn{2}{|l|}{$\begin{array}{l}\text { Penilaian } \\
\text { Validator }\end{array}$} & \multirow{2}{*}{$\begin{array}{l}\text { Rata- } \\
\text { rata }\end{array}$} & \multirow{2}{*}{ Kategori } \\
\cline { 3 - 5 } & V1 & V2 & \\
\hline 1 & Identitas & 4,0 & 4,0 & 4,0 & Baik \\
\hline 2 & Tujuan & 3,5 & 3,3 & 3,4 & Cukup Baik \\
\hline 3 & $\begin{array}{l}\text { Metode } \\
\text { belajar sesuai } \\
\text { dengan KD }\end{array}$ & 4,0 & 4,0 & 4,0 & Baik \\
\hline 4 & $\begin{array}{l}\text { Sarana dan } \\
\text { sumber belajar }\end{array}$ & 3,5 & 3,5 & 3,5 & Baik \\
\hline 5 & $\begin{array}{l}\text { Langkah } \\
\text { Pembelajaran }\end{array}$ & 3,5 & 3,5 & 3,5 & Baik \\
\hline 6 & Evaluasi & 3,7 & 3,3 & 3,5 & Baik \\
\hline 7 & Keterbacaan & 4,0 & 4,0 & 4,0 & Baik \\
\hline \multicolumn{2}{|l|}{ Reliabilitas } & $98 \%$ & & \\
\hline
\end{tabular}

Reliabilitas penilaian antara validator 1 dan validator 2 sebesar $98 \%$. RPP yang dikembangkan berkategori baik dan dapat digunakan dalam pembelajaran dengan sedikit revisi.

\section{B. Validasi Lembar Kegiatan Siswa (LKS)}

Lembar Kegiatan Siswa (LKS) merupakan lembar yang berisi pedoman bagi siswa untuk melakukan kegiatan terprogram (Depdikbud, 1995 dalam Ahmadi, 2011). LKS yang dikembangkan peneliti berupa LKS dengan model inkuiri terbimbing untuk melatihkan keterampilan memecahkan masalah. LKS memuat kegiatan merumuskan masalah, membuat hipotesis, mengidentifikasi variabel, merancang percobaan, mengambil data percobaan, menganalisis data, dan membuat kesimpulan.

Tabel 4. Hasil validasi hasil belajar siswa
LKS yang dikembangkan yaitu, LKS-1 berisi tentang sifat-sifat cermin datar, LKS-2 berisi tentang sifat-sifat cermin cekung, dan LKS-3 berisi tentang sifat-sifat cermin cembung.

Tabel 3. Hasil penilaian kualitas LKS

\begin{tabular}{|l|l|l|l|l|l|}
\hline \multirow{2}{*}{ No } & $\begin{array}{l}\text { Aspek yang } \\
\text { dinilai }\end{array}$ & \multicolumn{2}{|c|}{$\begin{array}{l}\text { Penilaian } \\
\text { Validator }\end{array}$} & $\begin{array}{l}\text { Rata- } \\
\text { rata }\end{array}$ & Kategori \\
\cline { 3 - 6 } & V1 & V2 & \\
\hline 1 & Organisasi LKS & 3.0 & 4.0 & 3.5 & Baik \\
\hline 2 & $\begin{array}{l}\text { Penjabaran } \\
\text { rangkaian } \\
\text { materi }\end{array}$ & 3.7 & 3.3 & 3.5 & Baik \\
\hline 3 & Prosedur & 3.5 & 3.3 & 3.4 & $\begin{array}{l}\text { Cukup } \\
\text { Baik }\end{array}$ \\
\hline 4 & Alat dan Bahan & 4.0 & 4.0 & 4.0 & Baik \\
\hline \multicolumn{3}{|c|}{ Reliabilitas } & $98.70 \%$ & & \\
\hline
\end{tabular}

Reliabilitas penilaian antara validator 1 dan validator 2 sebesar 98,70\%. LKS yang dikembangkan berkategori baik dan layak digunakan dengan revisi kecil.

C. Validasi Hasil Belajar Siswa

Soal tes hasil belajar siswa yang dikembangkan digunakan untuk memperoleh data tentang kevalidan soal tes hasil belajar siswa. Soal tes hasil belajar yang dikembangkan merujuk pada indikator pembelajaran yang telah disusun dalam RPP. Jumlah soal yang diujikan sebanyak 20 soal. Soal tes hasil belajar yang dikembangkan oleh peneliti divalidasi oleh 2 validator. Validator memberikan validasi terhadap soal tes hasil belajar pengetahuan meliputi empat kategori yaitu valid, cukup valid, kurang valid, dan tidak valid. Hasil validasi tes tersebut disajikan dalam Tabel 4.

\begin{tabular}{|c|c|c|c|c|c|c|c|c|}
\hline \multirow{2}{*}{ No. Butir Soal } & \multicolumn{3}{|c|}{ Validasi Isi } & \multirow{2}{*}{ Kategori } & \multicolumn{3}{|c|}{ Bahasa dan Penulisan Soal } & \multirow{2}{*}{ Kategori } \\
\hline & V1 & $\mathbf{V 2}$ & Rata-rata & & V1 & V2 & Rata-rata & \\
\hline 1 & 3,0 & 4,0 & 3,5 & Valid & 3,0 & 4,0 & 3,5 & Valid \\
\hline 2 & 4,0 & 4,0 & 4,0 & Valid & 4,0 & 4,0 & 4,0 & Valid \\
\hline 3 & 4,0 & 4,0 & 4,0 & Valid & 4,0 & 4,0 & 4,0 & Valid \\
\hline 4 & 3,0 & 3,0 & 3,0 & Cukup Valid & 3,0 & 3,0 & 3,0 & Cukup Valid \\
\hline 5 & 3,0 & 3,0 & 3,0 & Cukup Valid & 3,0 & 3,0 & 3,0 & Cukup Valid \\
\hline 6 & 4,0 & 4,0 & 4,0 & Valid & 4,0 & 4,0 & 4,0 & Valid \\
\hline 7 & 3,0 & 3,0 & 3,0 & Cukup Valid & 3,0 & 3,0 & 3,0 & Cukup Valid \\
\hline 8 & 4,0 & 4,0 & 4,0 & Valid & 4,0 & 4,0 & 4,0 & Valid \\
\hline 9 & 3,0 & 4,0 & 3,5 & Valid & 3,0 & 3,0 & 3,0 & Cukup Valid \\
\hline 10 & 3,0 & 4,0 & 3,5 & Valid & 3,0 & 3,0 & 3,0 & Cukup Valid \\
\hline 11 & 3,0 & 4,0 & 3,5 & Valid & 3,0 & 4,0 & 3,5 & Valid \\
\hline 12 & 4,0 & 4,0 & 4,0 & Valid & 4,0 & 4,0 & 4,0 & Valid \\
\hline 13 & 4,0 & 4,0 & 4,0 & Valid & 4,0 & 4,0 & 4,0 & Valid \\
\hline 14 & 3,0 & 3,0 & 3,0 & Cukup Valid & 3,0 & 3,0 & 3,0 & Cukup Valid \\
\hline 15 & 3,0 & 3,0 & 3,0 & Cukup Valid & 3,0 & 3,0 & 3,0 & Cukup Valid \\
\hline 16 & 4,0 & 4,0 & 4,0 & Valid & 4,0 & 4,0 & 4,0 & Valid \\
\hline 17 & 3,0 & 3,0 & 3,0 & Cukup Valid & 3,0 & 3,0 & 3,0 & Cukup Valid \\
\hline 18 & 4,0 & 4,0 & 4,0 & Valid & 4,0 & 4,0 & 4,0 & Valid \\
\hline 19 & 3,0 & 4,0 & 3,5 & Valid & 3,0 & 3,0 & 3,0 & Cukup Valid \\
\hline 20 & 3,0 & 4,0 & 3,5 & Valid & 3,0 & 3,0 & 3,0 & Cukup Valid \\
\hline Rata-rata & 3,4 & 3,7 & 3,6 & Valid & 3,4 & 3,5 & 3,5 & Cukup Valid \\
\hline Reliabilitas & \multicolumn{4}{|c|}{$95,8 \%$} & \multicolumn{4}{|c|}{$98,6 \%$} \\
\hline
\end{tabular}


Berdasarkan Tabel 4 di atas, dapat dinyatakan bahwa skor rata-rata hasil penilaian berkategori valid/dapat dipahami dan dapat digunakan (layak) sebagai instrumen tes hasil belajar pengetahuan dengan sedikit revisi.

\section{Validasi Keterampilan Memecahkan Masalah}

Tes keterampilan memecahkan masalah merupakan tes yang digunakan untuk mengetahui hasil belajar siswa pada aspek keterampilan memecahkan masalah setelah mengikuti proses belajar mengajar.

Kegiatan tersebut digunakan untuk mengukur kemampuan siswa yang meliputi merumuskan hipotesis, menentukan variabel eksperimen, melaksanakan eksperimen, menganalisis dan mengolah data, serta menyimpulkan hasil percobaan. Hasil validasi lembar tes keterampilan memecahkan masalah disajikan pada Tabel 5.

Tabel 5. Hasil validasi keterampilan memecahkan masalah

\begin{tabular}{|l|l|l|l|l|l|}
\hline \multirow{2}{*}{ No } & \multirow{2}{*}{$\begin{array}{l}\text { Aspek } \\
\text { yang } \\
\text { dinilai }\end{array}$} & \multicolumn{2}{|l|}{$\begin{array}{l}\text { Penilaian } \\
\text { Validator }\end{array}$} & Rata- & \multirow{2}{*}{ Kata } \\
\cline { 3 - 5 } & Vategori & V2 & & \\
\hline 1 & Isi & 3.5 & 3.5 & 3.5 & Baik \\
\hline 2 & Konstruksi & 3.5 & 3.3 & 3.4 & $\begin{array}{l}\text { Cukup } \\
\text { Baik }\end{array}$ \\
\hline 3 & Bahasa & 3.3 & 4.0 & 3.7 & Baik \\
\hline 4 & Waktu & 4.0 & 4.0 & 4.0 & Baik \\
\hline \multicolumn{2}{|l|}{ Reliabilitas } & $98.82 \%$ & & \\
\hline
\end{tabular}

Berdasarkan Tabel di atas, skor rata-rata lembar penilaian tes keterampilan memecahkan masalah berkategori baik dan dapat digunakan dengan sedikit revisi.

\section{KESIMPULAN}

\section{A. Simpulan}

Berdasarkan analisis hasil penelitian dan temuan di lapangan, maka dapat disimpulkan bahwa perangkat pembelajaran IPA berbasis inkuiri terbimbing untuk melatihkan keterampilan memecahkan masalah pada pokok bahasan cermin layak digunakan dalam proses pembelajaran.

\section{B. Saran}

Saran yang dapat peneliti kemukakan berdasarkan penelitian yang telah dilakukan dan hasil yang diperoleh adalah sebagai berikut: (1) pembelajaran dengan model inkuiri terbimbing memerlukan pengaturan waktu seefektif mungkin sehingga pembelajaran dapat berlangsung sesuai dengan tujuan yang telah ditentukan, (2) alat-alat dan bahan percobaan yang akan digunakan hendaknya terlebih dahulu disiapkan sebelum pelaksanaan kegiatan penelitian dilaksanakan, sehingga kegiatan penyelidikan dapat berjalan lancar, (3) guru perlu terus melatih siswanya untuk mengembangkan keterampilan memecahkann masalah melalui kegiatan penyelidikan agar siswa terbiasa melakukannya.

\section{REFERENSI}

Ahmadi, I.K. dan Amri, S. (2011). Pengembangan pembelajaran IPS terpadu. Jakarta: Prestasi Pustakarya.

Borich, D. (1994). Observation Skill for Effective Teaching. New York: Macmilan Publising Company.

Ibrahim, M. (2005). Asesmen berkelanjutan. Surabaya: Unesa University Press

Ratumanan, G.T., dan T, Laurens. (2006). Evaluasi Hasil Belajar yang Relevan dengan Kurikulum Berbasis Kompetensi. Surabaya: UNESA University Press. 